\title{
Melt-in-Mouth Multi-particulate System for the Treatment of ADHD: A Convenient Platform for Pediatric Use
}

\author{
Jalashri Patadia, ${ }^{1}$ Rahul Tripathi, ${ }^{2,3}$ and Amita $\mathrm{Joshi}^{2,3,4}$
}

Received 21 May 2015; accepted 4 September 2015; published online 21 September 2015

\begin{abstract}
Generally, pellets obtained from extrusion/spheronization, containing microcrystalline cellulose (MCC), do not disintegrate. An attempt has been made to develop melt-in-mouth pellets of taste-masked atomoxetine hydrochloride, using extrusion-spheronization, for pediatric patients. Melt-in-mouth pellets were prepared using extrusion-spheronization method and optimized using $3^{3}$ FFD. MCC $\left(\mathrm{X}_{1}, \%\right)$, mannitol $\left(\mathrm{X}_{2}, \%\right)$ and Indion 414: Pharmaburst 500 ratio $\left(\mathrm{X}_{3}\right.$, ratio) were the factors (independent variables) studied, whereas responses studied (dependent variables) were friability (Y1, \%), yield (Y2, \%) shape (Y3, roundness) in vitro disintegration time (Y4, seconds). The optimized formulation obtained from FFD was characterized for friability, shape and morphology, in vitro disintegration time, porosity, moisture uptake, in vitro release study and in vivo taste and disintegration time in healthy human volunteers. Randomized, two-treatment, two-sequence, two-period, single dose, crossover sensory evaluation study of taste-masked melt-in-mouth pellet was carried out in 10 healthy human subjects. A statistically significant polynomial mathematical relationship was generated between the factors and responses to obtain an optimized formulation. The optimized formulation was characterized (in vitro and in vivo) and exhibited a rapid drug release in vitro attributed to fast disintegration of pellets and high solubility of drug in $0.1 \mathrm{~N} \mathrm{HCl}$ and buffer ( $\mathrm{pH}$ 6.8). In vivo, $40 \%$ of volunteers ranked taste-masked optimized formulation as slightly bitter while $60 \%$ ranked it as no taste. The optimized pellets were conveniently administered in volunteers and exhibited rapid in-vivo disintegration in the oral cavity. Melt-in-mouth pellets can be a used as a platform technology for administering drugs to paediatric patients accurately and conveniently resulting in patient compliance.
\end{abstract}

KEY WORDS: full factorial design; oro-dispersible; pediatric; pellets; quality by design (QbD); taste masking.

\section{INTRODUCTION}

Drug product development for pediatric population still has special challenges. An ideal formulation for children should allow minimal dosage and frequency. Single variant of dosage form must comply or fit to all range of drugs, minimal impact on lifestyle, nontoxic excipients and convenient, easy and reliable administration. The biggest hurdle in the development of pediatric formulation is patient compliance and acceptability (1-3). The pediatric population encompasses a wide range of children from newborns to adolescents. Thus, it is necessary that formulation must be well accepted by most of the patients for effective and safe therapy.

Rahul Tripathi and Amita Joshi contributed equally to this work.

${ }^{1}$ Department of Pharmaceutics, NIPER Ahmedabad, Ahmedabad, 380054, India.

${ }^{2}$ Department of Pharmaceutics, B. V. Patel Pharmaceutical Education and Research Development (PERD) Centre, Ahmedabad, 380054, India.

${ }^{3}$ Adjunct faculty, Department of Pharmaceutics, NIPER Ahmedabad, C/o B.V. Patel PERD Centre, S.G. Highway, Thaltej, Ahmedabad, Gujarat 380054, India.

${ }^{4}$ To whom correspondence should be addressed. (e-mail: amitagarg4@gmail.com; amita@perdcentre.com)
Development of formulation, which suits to all age group of children, is a current challenge to the pharmaceutical scientists (1). The oral route of administration is the preferred one for children (4). Although tablets are generally easier and cheaper to develop, manufacture, transport, store and dispense than liquid medicines, the pediatric population often shows problems in swallowing the medications due to size, shape, unpleasant smell and taste (5). Conventional tablets and capsules have not been ideally designed for pediatric application. Tablets have either to be splited or crushed to adjust the dose, according to body weight of the patient $(6,7)$.

Multiparticulate systems can be useful platform for a variety of modern pediatric preparations such as orodispersible or melt-in-mouth system. Melt-in-mouth products are meant for oral cavity and may dissolve on the tongue in the presence of small amount of saliva or liquid. They are easy to administer and provides accuracy of dose (4). Since each individual unit of multi-particulate contains predetermined quantity of drug, the drug dose can be easily adjusted by measuring a specific amount/number of the pellets, depending on the patient's body weight. Thus, it also offers a dosing flexibility, an important prerequisite for a widely heterogeneous group of pediatric patients. Apart from the dosing flexibility, pellets offer the advantage that they can 
be sprinkled on food, mixed with fluids or directly swallowed, improving patient compliance (8). Consequently, such formulation approach seems to provide easy and flexible administration and high patient compliance, assuring the effective and safe therapy (9).

We propose to use combination approach of orodispersible system or melt-in-mouth approach along with multiparticulate drug delivery system. The melt-in-mouth multiparticulate drug delivery system consists of drug-loaded uniform spherical pellets (size: 0.5 to $1.5 \mathrm{~mm}$ ) and capable of dissolving immediately when placed on the tongue. These pellets can be successfully developed using extrusion and spheronization technique. Melt-in-mouth multiparticulate system offers a "flexible oro-dispersible drug delivery technology" for the delivery of drugs in pediatric population which:

- Offers ease of dosing flexibility with respect to age group and body weight

- Patient acceptance with respect to taste and ease to swallow

- Storage and transportation, thus reducing supply challenges, improved palatability over liquid formulations and storage problems

Atomoxetine hydrochloride is the FDA-approved nonstimulant, selective norepinephrine reuptake inhibitor used for the treatment of attention deficit/hyperactivity disorder (ADHD) in children as well as in adults. ADHD is one of most common childhood brain disorders and can continue until adolescence and adulthood. Symptoms include difficulty in staying focused and paying attention, difficulty in controlling behaviour and hyperactivity (overactivity). It selectively inhibits the reuptake of norepinephrine $(10,11)$.

In general, emesis is preceded with nausea, and in such condition, it is difficult to administer drug with a glass of water; hence, it is beneficial to administer such drugs as dispersible dosage form. Atomoxetine hydrochloride is an intensely bitter drug $(12,13)$; hence, if it is incorporated directly into an oro-dispersible dosage form, the main objective behind formulation of such a dosage form will definitely get futile. Hence, in the present work, we developed and optimized, taste-masked multi-particulate system of atomoxetine hydrochloride using quality by design (QbD) approach, which dissolves rapidly into the oral cavity. Our primary aim is to develop such a dosage form which dissolve or disintegrate in the oral cavity without drinking water. Thus, it would be suitable for the patients with swallowing or chewing difficulties especially pediatrics or geriatrics.

\section{MATERIALS}

Atomoxetine hydrochloride was provided as a gift sample by Sun Pharmaceuticals, Vadodara, India. Kyron T 314 and Kyron T 134 were obtained as gift samples from Corel Pharma Chem, India. Pharmaburst $500^{\circledR}$ was obtained as gift samples from SPI Pharma, India. Microcrystalline Cellulose PH 101 (FMC Biopolymer, Ireland), mannitol (Signet Chemicals, India), lactose monohydrate (Lactose India Ltd.) and L Hydroxy propylcellulose-LH 32 (Shin-Etsu, Japan) were used as excipients and procured from indicated sources. Indion 414 was obtained as a gift sample from Ion-exchange, India. All materials and reagents were of analytical grade and used as received.

\section{EXPERIMENTAL METHODS}

\section{Taste Masking of Atomoxetine Hydrochloride}

Kyron T-134 was used in different ration for taste-making of atomoxetine hydrochloride (bitter in taste) using slurry method with water as a solvent (14). In this method, Kyron $\mathrm{T} 134$ was soaked in solvent for $1 \mathrm{~h}$ followed by addition of the drug. This aqueous mixture was triturated for $30 \mathrm{~min}$ and dried at $80-90^{\circ} \mathrm{C}$ in order to obtain drug-kyron complex. Taste masking of the drug in the complex was characterized using DSC analysis (DSC Q20 V24.9 Build 121, TA Instrument, USA) and sensory evaluation in healthy human volunteers.

\section{Pellet Preparation Using Extrusion and Spheronization}

All the excipients along with taste-masked active (kyrondrug complex), except binder (L HPC LH 32) were pre-mixed for $10 \mathrm{~min}$, as per the factorial design (Tables I and II). The dry blend was then granulated with an aqueous binder solution of L HPC LH 32 in order to obtain a wet mass. Extrudates were obtained by feeding the wet mass in gravity fed cylinder extruder (R. R. Enterprises, India). Extrudates were spheronized in spheronizer ( $R$. $R$. Enterprises, India) to obtain spherical pellets. The pellets were dried in fluidized bed processor (Nero-Aeromatic, Switzerland) at $60^{\circ} \mathrm{C}$ for $10 \mathrm{~min}$. The dried pellets were then evaluated for yield (\%), shape of the pellets, friability (\%) and disintegration time. Based on the preliminary trial batches (Table I), independent factors and factor levels were identified.

Once the formulation was optimized, a melt-in-mouth formulation of unmasked atomoxetine hydrochloride was also prepared with similar composition.

\section{Experimental Design}

A $3^{3}$ full factorial design (FFD), with three centre points, was used to optimize the pellet formulation. MCC concentration $\left(\mathrm{X}_{1}, \%\right)$, mannitol concentration $\left(\mathrm{X}_{2}, \%\right)$ and Indion 414: Pharmaburst 500 ratio $\left(\mathrm{X}_{3}\right.$, ratio) were three factors (independent variables) studied. The levels for the $\mathrm{X}_{1}, \mathrm{X}_{2}$ and $\mathrm{X}_{3}$ were chosen in accordance with the preliminary data. The responses (dependent variables) studied were friability $\left(\mathrm{Y}_{1}, \%\right)$, yield $\left(\mathrm{Y}_{2}, \%\right)$, shape of pellets $\left(\mathrm{Y}_{3}\right.$, roundness $)$ and disintegration time $\left(\mathrm{Y}_{4}\right.$, seconds). Table I summarizes independent and dependent variables along with their levels. Various response surface methodology computations were performed employing Design-Expert ${ }^{\circledR}$ software (Version 7.1.2, Stat-Ease Inc., Minneapolis, MN). All the 29 experimental runs are enlisted in Table II. 
Table I. Factors (Independent Variables), Factor Levels and Responses (Dependent Variables) Used in $3^{3}$ Full Factorial Experimental Designs

\begin{tabular}{lllll}
\hline Factors & \multicolumn{3}{c}{ Factor level used } & Responses \\
\cline { 2 - 4 } & -1 & 0 & +1 & $Y_{1}=$ Friability (\%) \\
\hline $\mathrm{X}_{1}=$ MCC (\%) & 20 & 25 & 30 & $Y_{2}=$ Yield (\%) \\
$\mathrm{X}_{2}=$ mannitol (\%) & 10 & 12.5 & 15 & $Y_{3}=$ Shape of pellets \\
$\mathrm{X}_{3}=$ Indion 414: Pharmaburst 500 (ratio) & 0.33 & 0.50 & 0.67 & $Y_{4}=$ Disintegration time (seconds) \\
\hline
\end{tabular}

\section{Statistical data analysis and validation of the optimization model}

Design-Expert ${ }^{\circledR}$ software (Version 7.1.2, Stat-Ease Inc., Minneapolis, MN) was used in the current study for generation and evaluation of statistical experimental design. Polynomial models including interaction terms were generated for all the response variables using multiple linear regression analysis. Graphical representations for influence of factors and their interaction were generated. In order to validate the polynomial equations, one optimum checkpoint (formulation composition and process) and two random checkpoints were selected by intensive grid search performed over the entire experimental domain. Formulations corresponding to these three check points were prepared and evaluated for all four responses $\left(\mathrm{Y}_{1}\right.$ to $\left.\mathrm{Y}_{4}\right)$. The resultant

Table II. Test Runs Carried out for the Preparation of Atomoxetine Hydrochloride Melt-in-Mouth Pellets as per $3^{3}$ Full Factorial Design

\begin{tabular}{cccc}
\hline Test run & $\mathrm{X}_{1}(\mathrm{MCC})$ & $\mathrm{X}_{2}$ (mannitol) & $\mathrm{X}_{3}$ (Indion 414: \\
$\% w / w$ & $\% w / w$ & Pharmaburst 500) ratio
\end{tabular}

\begin{tabular}{|c|c|c|c|}
\hline 1 & 0 & 1 & 1 \\
\hline 2 & -1 & 1 & 0 \\
\hline 3 & 0 & -1 & 1 \\
\hline 4 & -1 & -1 & -1 \\
\hline 5 & 0 & -1 & 0 \\
\hline 6 & -1 & 0 & 1 \\
\hline 7 & 0 & 0 & 0 \\
\hline 8 & 1 & 0 & 1 \\
\hline 9 & 0 & 0 & 1 \\
\hline 10 & 0 & -1 & -1 \\
\hline 11 & -1 & 0 & -1 \\
\hline 12 & -1 & 0 & 0 \\
\hline 13 & -1 & -1 & 1 \\
\hline 14 & 1 & 1 & 0 \\
\hline 15 & 1 & 0 & -1 \\
\hline 16 & 1 & -1 & 0 \\
\hline 17 & 1 & -1 & -1 \\
\hline 18 & 0 & 1 & 0 \\
\hline 19 & 1 & 1 & 1 \\
\hline 20 & -1 & 1 & -1 \\
\hline 21 & 0 & 0 & -1 \\
\hline 22 & 0 & 1 & -1 \\
\hline 23 & 1 & 0 & 0 \\
\hline 24 & -1 & 1 & 1 \\
\hline 25 & -1 & -1 & 0 \\
\hline 26 & 1 & -1 & 1 \\
\hline 27 & 1 & 1 & -1 \\
\hline 28 & 0 & 0 & 0 \\
\hline 29 & 0 & 0 & 0 \\
\hline
\end{tabular}

experimental data of response properties were subsequently compared quantitatively with the predicted values. Also, the linear regression plots between observed and predicted values of the response properties were drawn using MS-Excel ver. 2010 (15).

\section{Characterization of Melt-in-Mouth Pellet Formulation of Atomoxetine Hydrochloride}

\section{Usable Yield (\% Theoretical)}

The usable yield of pellets was determined from sieve analysis, which was carried out using a sieve shaker (EMS 8, Electrolab, India) equipped with $(600-2360 \mu)$ sieves, at amplitude of $2 \mathrm{~mm}$, for $5 \mathrm{~min}$. The pellet yield was calculated based on the pellet fraction between \#14/22 and presented as the percent of total pellet weight. This size fraction was considered as a measurement tool for different batches of pellets (16).

\section{Pellet Sphericity and Shape Analysis}

The pellet sphericity and shape were determined using an image analysis system. Photographs of pellets were taken under a light microscope system at a magnification of $\times 4$. The captured images were analysed by image analysis software (BA210 Digital, Motic Instruments, India). Around 10 pellets were analysed form every batch. Each individual pellet was subjected for shape factor, roundness $(16,17)$. The formula to calculate the roundness is as follows:

Roundness $=\frac{\text { Area }}{\pi \text { XRadius X Radius }}$

\section{Friability}

Six grams of pellets from usable yield were weighed accurately and subjected to friability test along with 25 stainless steel balls ( $3 \mathrm{~mm}$, dia.) in Roche friabilator (Electrolab $\mathrm{EF} 2$, India) at $25 \mathrm{rpm}$ for $4 \mathrm{~min}$ (i.e. 100 revolutions) (16). The $\%$ friability was determined using following equation:

$F=\left(1-\frac{W t}{W 0}\right) \times 100$

Where $\mathrm{W}_{0}=$ Initial weight of pellets and $\mathrm{W}_{\mathrm{t}}=$ weight after 100 revolutions. 
Porosity

Porosity was calculated using the following Eq. (3), for percent effective porosity $(18,19)$

$\% \varepsilon=[(\rho t-\rho b) / \rho b] \times 100$

Where $\varepsilon=$ effective porosity, $\rho \mathrm{t}=$ true density and $\rho \mathrm{b}=$ bulk density. The true density of the powder formulation was determined in triplicate using Helium pycnometry (Smart Pycno 30, Smart Instruments, Mumbai).

\section{In Vitro Disintegration Test}

Modified disintegration test apparatus (Electrolab ED $2 \mathrm{~L}$, India) was used for measuring the disintegration time of pellets. The assembly containing a hollow cylinder and 6 test tubes was modified by replacing the 10\# mesh screen with 24\# mesh screen. Each pellet was kept in the tube individually and subjected to disintegration test; the time to disintegrate the pellet was recorded $(20,21)$.

\section{Moisture Uptake Behaviour}

Single pellet was kept on a glass slide lined with a tissue paper and observed under light microscope (BA210 Digital, Motic Instruments). Water was added dropwise on tissue paper (to make it wet) using a dropper and further moisture uptake behaviour by the pellet was observed under microscope at a magnification $\times 4$ (22).

\section{Surface Morphology Study Using Scanning Electron Microscope}

Surface morphology and cross sectional view of the meltin-mouth pellet was examined by scanning electron microscope (SEM) (Ultra-55 Carl Zeiss Field emission scanning electron microscope). The samples were prepared by gently sprinkling the pellets on a double adhesive tape, which is stuck to an aluminium stub. The stubs were then coated with gold using a sputter coater under high vacuum and high voltage to achieve a film thickness of $30 \mathrm{~nm}$. The samples were then imaged using a $3-\mathrm{kV}$ electron beam. The images were obtained at the magnification between $\times 150$ and $\times 2000$.

\section{Drug Content}

Atomoxetine hydrochloride content in the pellets was assayed by a validated first derivative spectrophotometeric method using UV-Vis spectrophotometer (Shimadzu UV1800, Japan) at $229 \mathrm{~nm}$ wavelength. The analytical method was found to be specific, linear in the concentration range of $5-50 \mu \mathrm{g} / \mathrm{ml}$, precise (\% CV: $1.05-1.73$ ) and accurate (98.5-102.0\%).

\section{In Vitro Drug Release Study}

In vitro drug release study of atomoxetine hydrochloride pellets was carried out in USP apparatus III (41-500-061, Hanson Research Corporation, USA). Atomoxetine hydrochloride pellets equivalent to $25 \mathrm{mg}$ were evaluated for the dissolution studies. The test was carried out in USP dissolution apparatus III, at $5 \mathrm{dpm}$ (dips per min.), using $250 \mathrm{ml} 0.1 \mathrm{~N}$ $\mathrm{HCl}$ and in simulated salivary fluid ( $\mathrm{pH} \mathrm{6.8)} \mathrm{as} \mathrm{media.} \mathrm{Aliquot} \mathrm{of}$ $5 \mathrm{ml}$ was withdrawn and replaced with fresh media at $5,10,15$, 20, 30, 45, 60 and $90 \mathrm{~min}$. The dissolution samples were analysed by validated first derivative spectrophotometeric method and drug release was calculated. The analytical method was found to be specific, linear in the concentration range of $5-50 \mu \mathrm{g} / \mathrm{ml}$, precise (\% CV: $1.05-1.73$ for $0.1 \mathrm{~N} \mathrm{HCl}$ and 1.23-1.65 in PBS, $\mathrm{pH} 6.8)$ and accurate $(98.5-102.0 \%$ for $0.1 \mathrm{~N} \mathrm{HCl}$ and $98.2-$ $102.5 \%$ in PBS, pH 6.8) (15).

Sensory Evaluation of Taste-Masked Melt-in-Mouth Pellets
of Atomoxetine Hydrochloride in Healthy Human Volunteers

\section{Clinical Protocol}

A randomized, two-treatment, two-sequence, two-period, single-dose, crossover sensory evaluation study of tastemasked melt-in-mouth pellet formulation of atomoxetine hydrochloride in 10 healthy, adult, male/female, human subjects under fed condition was carried out. The study protocol was approved by the Institutional Ethics Committee (Study No. BA040414, B.V. Patel PERD Centre, Ahmedabad, India).

All the subjects underwent a screening prior to the day of first dosing. Volunteers gave a written informed consent after receiving a detailed explanation of the investigational nature of the study. Selected volunteers were non-smokers and were judged healthy on the basis of their medical history, physical examination and haematological parameters in blood.

Upon entering into the study, the subjects were housed in the clinical facility of the trial site for $30 \mathrm{~min}$ prior to dosing, until $1 \mathrm{~h}$ post-dose in each of the two periods. The study was conducted in a randomized crossover design. Mouth dissolving pellets (around 10-12 in number $\approx 1 \mathrm{mg}$ of drug) of atomoxetine hydrochloride (each pellet contains $90 \mu \mathrm{g}$ of the drug), with and without taste-masking, were administered as per the randomization schedule. The time interval between periods was 2 days. The pellets were allowed to disintegrate, and the time taken by pellets to disintegrate in the oral cavity of the volunteers and the perception of the taste of the given formulation was recorded. Thereafter, the whole dose was spited out once sensory evaluation was completed. The oral cavity was cleansed with plain water thereafter (14).

The volunteers were asked to record their perception for the taste of the pellet formulation and the disintegration time for the pellets on the response sheet given to each of them. A sample response sheet is shown as Table III, which indicates the evaluation criteria for both, taste perception and in vivo disintegration time. Volunteers were asked to tick $(\sqrt{ })$ in any of the given options based on their perception. The responses of all the volunteers collected were statistically evaluated using Wilcoxon signed rank test (23).

\section{RESULTS AND DISCUSSION}

\section{Taste Masking of Atomoxetine Hydrochloride}

Atomoxetine hydrochloride is an extremely bitter tasting drug, and hence, taste masking of the active is an important 
Table III. Sample Response Sheet to Record Sensory Evaluation for Taste Perception and Disintegration Time of Melt in Mouth Pellets

\begin{tabular}{llll}
\hline \multicolumn{4}{c}{ Disintegration time } \\
\hline Loss than 1 minute & Taste perception & \\
\hline Not bitter & Slightly bitter & Very bitter \\
$(-)$ & $(+)$ & Extremely bitter \\
\hline
\end{tabular}

aspect in pediatric formulation development. For taste masking of atomoxetine hydrochloride, Kyron T 134 was used. Chemically, Kyron T 134 is Potassium methacrylatedivinylbenzene copolymer. Aqueous slurry method was used and ratio of drug/polymer, 1:3 found to be efficient enough to mask the taste of atomoxetine hydrochloride, successfully. The usage of tasteless resin, Kyron T134 (24), in substantially higher amount in comparison to the drug (drug/resin, 1:3) results in taste masking of the drug in the drug-resin complex. This was experimentally confirmed using DSC analysis. The DSC analysis of above mixture confirmed the complex formation (Fig. 1) (23). The sharp melting endothermic peak of atomoxetine hydrochloride at $169.19^{\circ} \mathrm{C}$ completely disappears in the complex (Drug and Kyron T 134). Further assurance of taste masking of the complex was carried out using sensory evaluation in healthy human volunteers, mentioned in "Sensory Evaluation for Taste Masking and In Vivo Disintegration Time of the Optimized Melt-in-Mouth Pellets of Atomoxetine Hydrochloride" section.

\section{Selection of Factors and Optimization of Pellet Formulation Using Response Surface Methodology}

During the preliminary trials, it was found that MCC, an extrusion-spheronization aid, is essential to prepare spherical pellets. Literature also supports the fact that MCC is the most

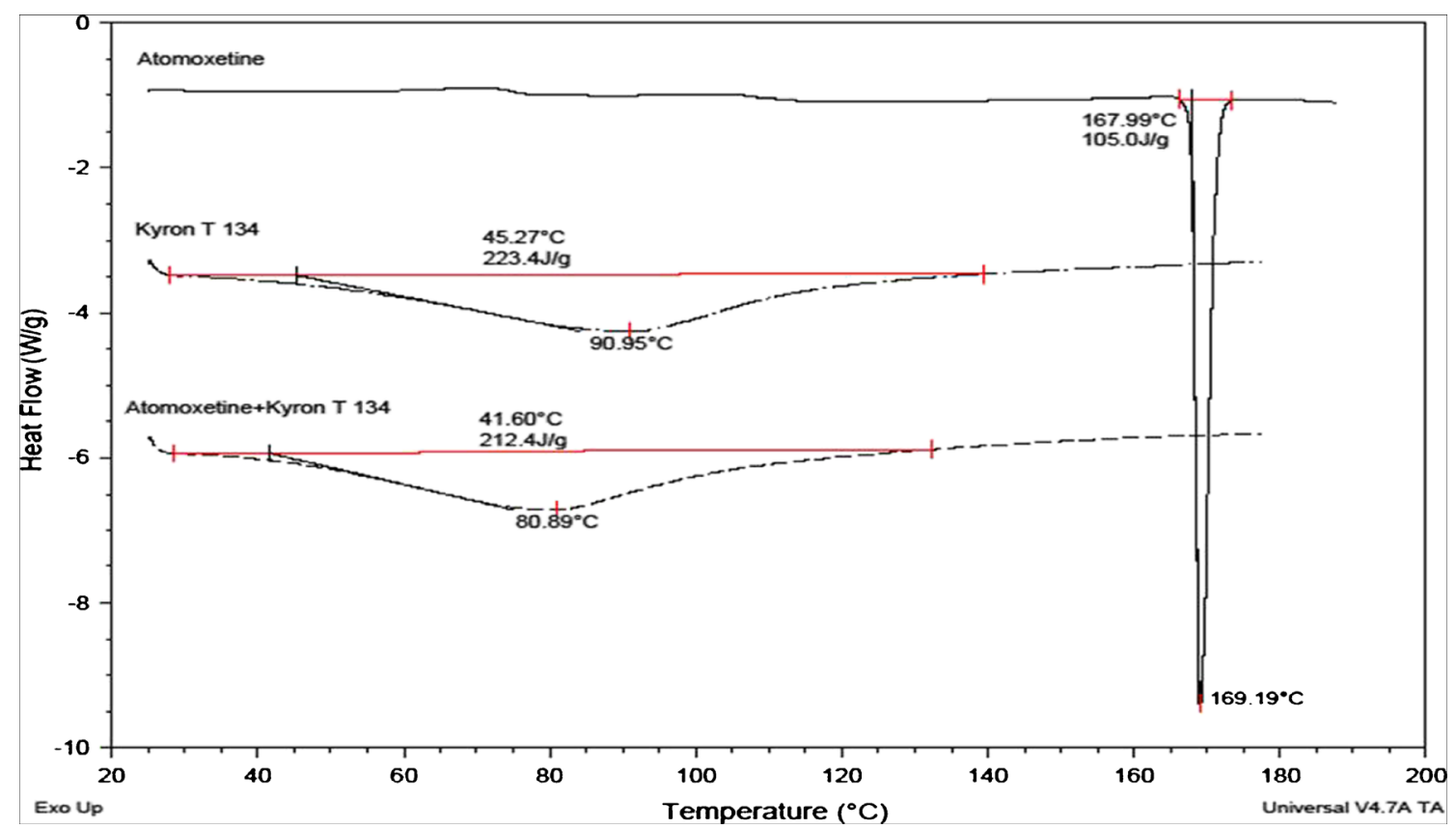

Fig. 1. DCS curves of atomoxetine hydrochloride, Kyron T 134 and complex of Atomoxetine hydrochloride and Kyron T 134 
Table IV. Test run Responses Carried out as per $3^{3}$ Full Factorial Design

\begin{tabular}{|c|c|c|c|c|}
\hline Test run & $\begin{array}{c}\mathrm{Y}_{1} \\
\text { Friability } \\
(\%)\end{array}$ & $\begin{array}{c}\mathrm{Y}_{2} \\
\text { Yield } \\
(\%)\end{array}$ & $\begin{array}{c}\mathrm{Y}_{3} \\
\text { (Roundness) }\end{array}$ & $\begin{array}{c}\mathrm{Y}_{4} \\
\mathrm{DT} \\
\text { (seconds) }\end{array}$ \\
\hline 1 & 1.7 & 27.6 & 60.114 & 40 \\
\hline 2 & 0.867 & 52.8 & 86.338 & 60 \\
\hline 3 & 1.7 & 22.8 & 87.781 & 30 \\
\hline 4 & 0.7 & 53.8 & 80.71 & 270 \\
\hline 5 & 0.93 & 33.8 & 73.372 & 55 \\
\hline 6 & 1.58 & 20.2 & 66.737 & 35 \\
\hline 7 & 0.63 & 34.2 & 71.073 & 85 \\
\hline 8 & 0.93 & 29.4 & 78.259 & 115 \\
\hline 9 & 1.4 & 24.6 & 64.57 & 55 \\
\hline 10 & 0.3 & 47.6 & 87.922 & 160 \\
\hline 11 & 0.75 & 60 & 87.634 & 400 \\
\hline 12 & 0.817 & 43 & 88.338 & 190 \\
\hline 13 & 1.1 & 23.8 & 59.49 & 25 \\
\hline 14 & 0.88 & 32.8 & 80.337 & 110 \\
\hline 15 & 0.98 & 44.8 & 90.056 & 300 \\
\hline 16 & 0.43 & 36.6 & 91.799 & 200 \\
\hline 17 & 0.616 & 47.3 & 84.85 & 250 \\
\hline 18 & 1.03 & 47.8 & 88.356 & 290 \\
\hline 19 & 0.467 & 57.4 & 90.576 & 280 \\
\hline 20 & 1.03 & 60.4 & 81.88 & 300 \\
\hline 21 & 0.1 & 49 & 88.082 & 300 \\
\hline 22 & 0.15 & 52.2 & 94.643 & 300 \\
\hline 23 & 0.53 & 41.6 & 68.292 & 80 \\
\hline 24 & 1.03 & 28 & 80.6 & 30 \\
\hline 25 & 0.48 & 33.6 & 83.38 & 35 \\
\hline 26 & 0.633 & 32 & 62.72 & 50 \\
\hline 27 & 0.667 & 32.2 & 77.49 & 35 \\
\hline 28 & 0.25 & 39.2 & 84.093 & 70 \\
\hline 29 & 0.38 & 48.4 & 93.213 & 180 \\
\hline
\end{tabular}

important in extrusion-spheronization (25). It is established that MCC pellets do not disintegrate, and drug release occurs via diffusion through an insoluble inert matrix (26). Hence, to obtain melt-in-mouth pellets, superdisintegrant and soluble

(a)

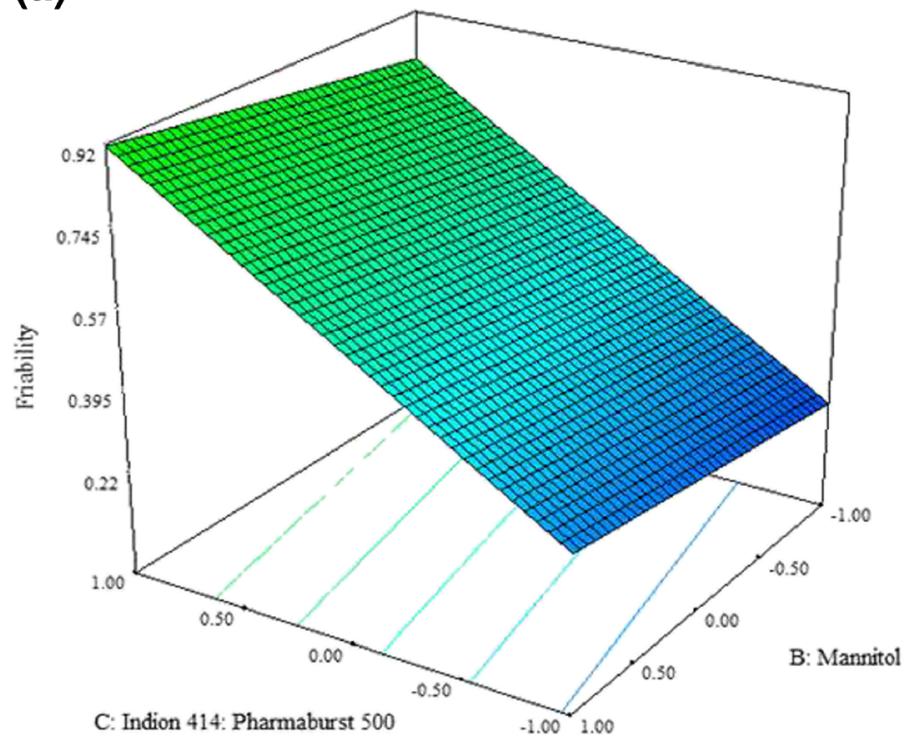

diluents were added to the pellet composition. Mannitol and lactose were used as soluble diluents and were found to assist in easy disintegration of the pellets. Various superdisintegrants were also evaluated viz., Indion 414, Pearlitol Flash, Pharmaburst 500, Prosolv SMCC, Ac-di-sol, Glycolys and FMelt $(21,24)$. In most of the cases of preliminary trials, inclusion of the higher amount of superdisintegrants reduced the pellet yield. Pellets containing Pharmaburst 500 resulted in high yield; however, the pellets did not burst within desired duration, in vitro, $1 \mathrm{~min}$. On the other hand, Indion 414 containing pellets were found to disintegrate within $30 \mathrm{~s}$ in vitro; however, inclusion of higher amount of Indion 414 reduced the pellet yield. Thus, combination of Pharmaburst 500 and Indion 414 could be used as superdisintegrant in the pellet composition to achieve disintegration in the predetermined time period.

Based on preliminary trials, simultaneous effect of MCC concentration, manitol and superdisintegrant ratio was selected and optimized by using $3^{3}$ full factorial experimental design with three centre points, wherein each factor was studied at 3 levels (Table I). A $3^{3}$ full factorial design (FFD) was applied for the optimization of melt-in-mouth pellet of atomoxetine hydrochloride. Various batches of pellet formulations were prepared as per the compositions mentioned in Tables I and II. A mathematical relation was generated between the factors (independent variables) and responses (dependent variables) using statistical Design-Expert ${ }^{\circledR}$ software for determining the level of factors, which yield desired responses. Responses obtained from all 29 tests run are depicted in Table IV.

Mathematical relationship was generated between the factors and responses for determining the levels of factors, which yield optimum responses. A second-order polynomial regression equation that fitted to the data is as follows:

$$
\begin{aligned}
\mathbf{Y}= & \mathbf{b}_{\mathbf{0}}+\mathbf{b}_{\mathbf{1}} \mathbf{X}_{\mathbf{1}}+\mathbf{b}_{\mathbf{2}} \mathbf{X}_{\mathbf{2}}+\mathbf{b}_{\mathbf{3}} \mathbf{X}_{\mathbf{3}}+\mathbf{b}_{\mathbf{4}} \mathbf{X}_{\mathbf{1}}{ }^{2}+\mathbf{b}_{\mathbf{5}} \mathbf{X}_{\mathbf{2}}{ }^{2} \\
& +\mathbf{b}_{\mathbf{6}} \mathbf{X}_{\mathbf{3}}{ }^{\mathbf{2}}+\mathbf{b}_{\mathbf{1 2}} \mathbf{X}_{\mathbf{1}} \mathbf{X}_{\mathbf{2}}+\mathbf{b}_{\mathbf{1 3}} \mathbf{X}_{\mathbf{1}} \mathbf{X}_{\mathbf{3}}+
\end{aligned}
$$

\section{(b)}

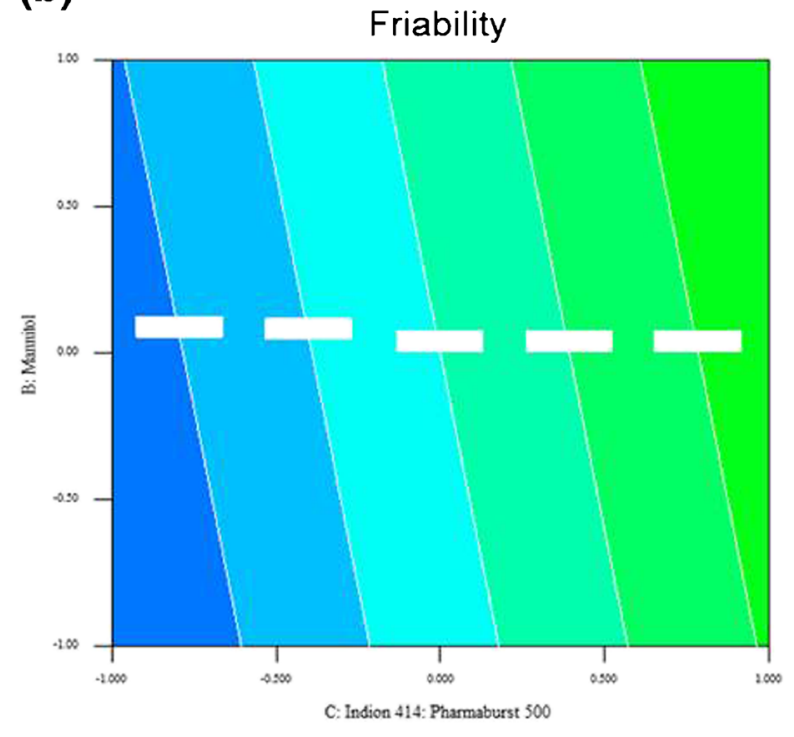

Fig. 2. a RSM plot and $\mathbf{b}$ contour plot showing effect of $X_{1}, X_{2}$ and $X_{3}$ on friability of melt-in-mouth atomoxetine hydrochloride pellets 
(a)

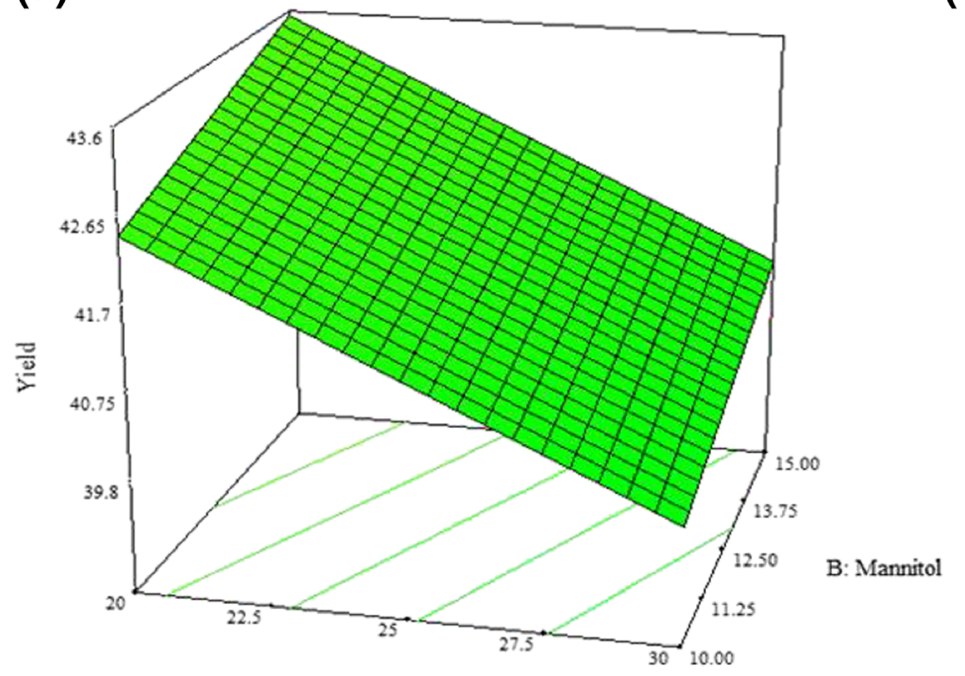

(b)

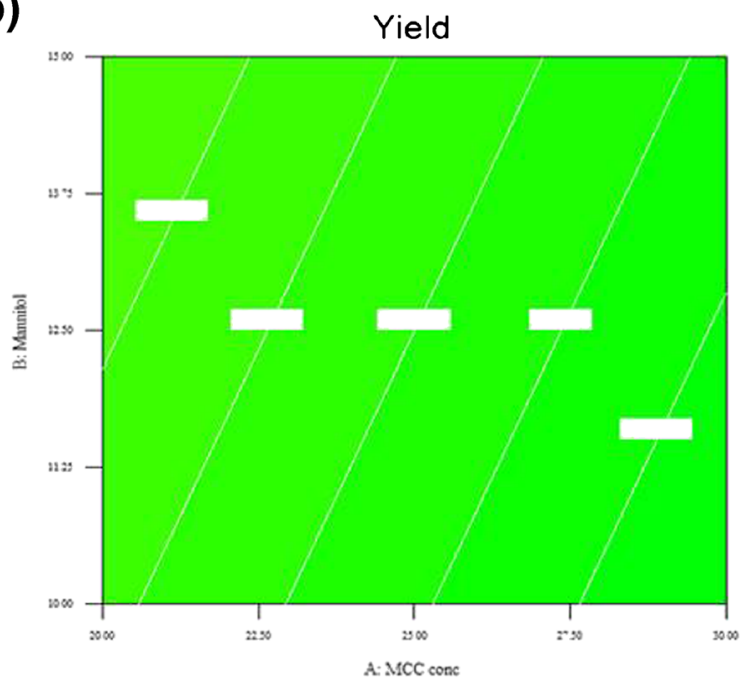

A: $\mathrm{MCC}$ conc

Fig. 3. a RSM plot and $\mathbf{b}$ contour plot showing effect of $X_{1}, X_{2}$ and $X_{3}$ on yield of melt-in-mouth atomoxetine hydrochloride pellets

Where $b_{0}$ is the intercept representing the arithmetic averages of all the quantitative outcomes of eight experimental runs, $b_{1}$ to $b_{3}$ are the coefficients computed from the observed experimental values of $Y$ for $X_{1}, X_{2}$, and $X_{3}$. $\mathrm{X}_{1}, \mathrm{X}_{2}$ and $\mathrm{X}_{3}$ are the coded levels of factors. Equation 4 represents the quantitative effect of factors $\left(X_{1}, X_{2}\right.$ and $\mathrm{X}_{3}$ ) upon each of the responses: $\mathrm{Y}_{1}$ to $\mathrm{Y}_{4}$. Coefficients with one factor represent the effect of that particular factor while the coefficients with more than one factor represent the interaction between those factors. A positive sign in front of the terms indicates synergistic effect while negative sign indicates antagonistic effect of the factors. ANOVA was applied for estimating the significance of the model at $5 \%$ significance level. A model is considered significant if the $p$ value is less than 0.05 . The 3 -dimensional response surface plots were drawn to estimate the effect of independent variables on each response.

\section{Friability}

The regression equation for friability in actual values is given in Eq. 5. The equation represents the quantitative effect of factors $\left(\mathrm{X}_{1}, \mathrm{X}_{2}\right.$ and $\left.\mathrm{X}_{3}\right)$ upon the response $\mathrm{Y}_{1}$.

$\mathrm{Y}_{1}=-0.66518-0.00334 \mathrm{X}_{1}+0.031911 \mathrm{X}_{2}+1.84542 \mathrm{X}_{3}$

Coefficient with one factor represents the effect of that particular factor; positive sign indicates synergistic (a)

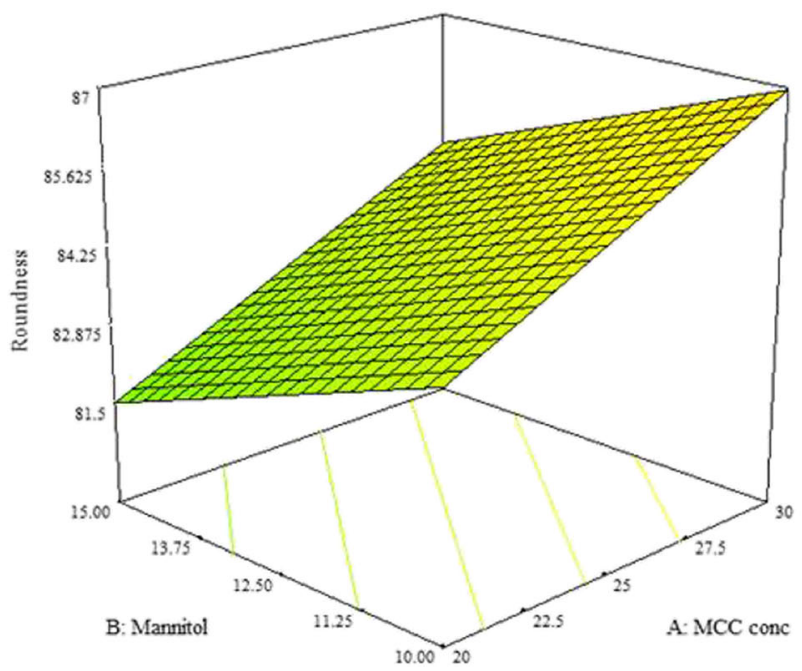

(b)

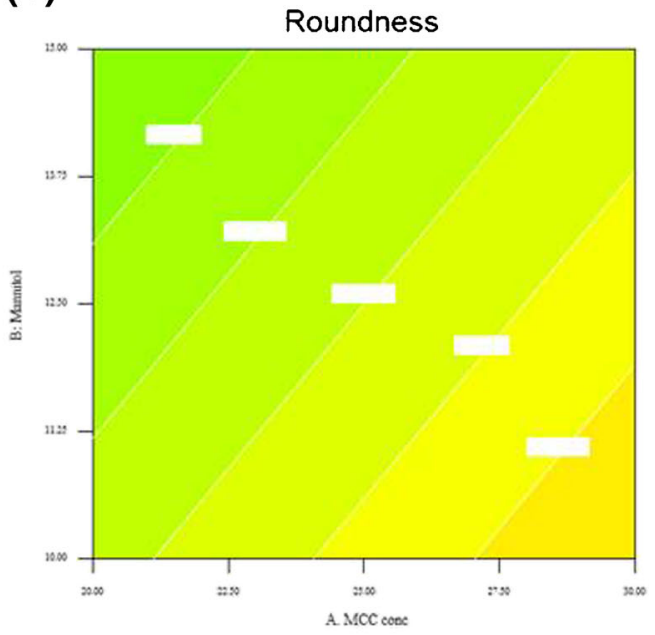

Fig. 4. a RSM plot and $b$ contour plot showing effect of $X_{1}, X_{2}$ and $X_{3}$ on roundness of melt-in-mouth atomoxetine hydrochloride pellets 
(a)

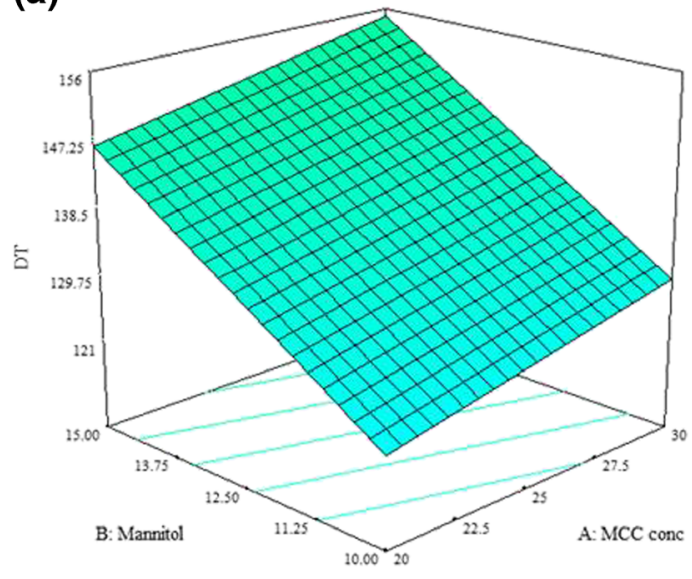

(b)

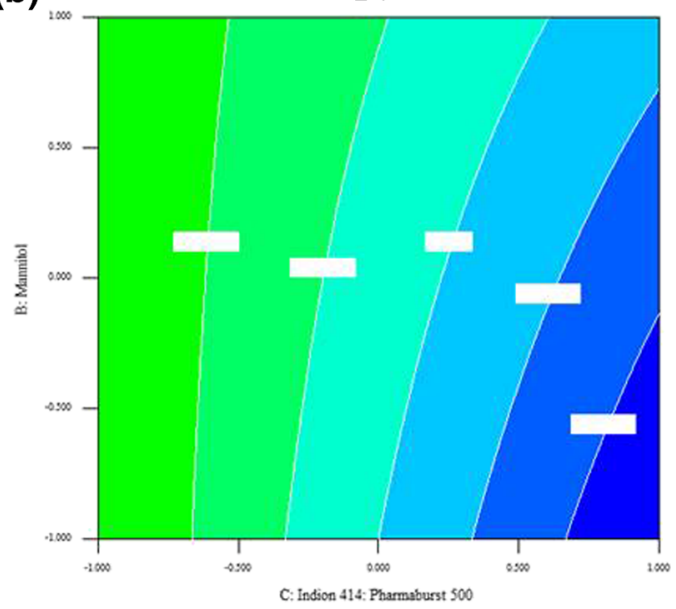

Fig. 5. a RSM plot and $\mathbf{b}$ contour plot showing effect of $X_{1}, X_{2}$ and $X_{3}$ on disintegration time of melt-in-mouth atomoxetine hydrochloride pellets

effect. The influence of concentration of MCC, mannitol and ratio of superdisintegrants on friability is shown in Fig. 2a. Graphical analysis revealed that friability varied in a nearly linear ascending pattern with the increase in superdisintegrants level as well as mannitol. However, the increase in friability is steeper with the increase in superdisintegrants level. The same is indicated from the Eq. 5 wherein factor $X_{3}$ has higher value of coefficient than other two factors. On the other hand, increasing the concentration of MCC decreases the friability, as indicated by the negative coefficient of $X_{1}$ in Eq. 5. However, the effect of superdisintegrant ratio seems to be more pronounced, as clearly depicted from Fig. 2a and coefficients in Eq. 5. From contour plot (Fig. 2b), it could be seen that friability is minimum at the lowest ratio of Indion 414: Pharmaburst $500\left(\mathrm{X}_{3}=0.33\right)$ and at high concentration of mannitol $\left(\mathrm{X}_{2}=15 \% \mathrm{w} / \mathrm{w}\right)$ with a constant amount of $\operatorname{MCC}\left(\mathrm{X}_{1}=25 \% w / w\right)$.

Analysis of variance (ANOVA) was applied for estimating the significance of the model at $5 \%$ significance level. A factor is considered to influence the response significantly, if the $p$ value is less than 0.05. From ANOVA, ratio of Indion 414: Pharmaburst $500\left(\mathrm{X}_{3}\right)$ was found to exert significant effect on friability $(p<0.05)$.

\section{Yield}

The regression equation for yield in actual values is given in Eq. 6. The equation represents the quantitative effect of factors $\left(\mathrm{X}_{1}, \mathrm{X}_{2}\right.$ and $\left.\mathrm{X}_{3}\right)$ upon the response $\mathrm{Y}_{2}$.

$$
Y_{2}=+83.42734-0.26111 \mathrm{X}_{1}+0.21556 \mathrm{X}_{2}-75.78431 \mathrm{X}_{3}(6)
$$

The influence of concentration of MCC, mannitol and ratio of superdisintegrants on yield is shown in Fig. 3a. Graphical analysis shows that yield varies linearly in an ascending pattern with the change in factors (Fig. 3a, b). Increasing the concentration of MCC decreases the pellet yield. Results indicated that increasing the ratio of Indion 414:Pharmaburst 500 decreases yield of pellets, with higher value of coefficient than other two factors in Eq. 6, while increasing the concentration of mannitol increases yield. Thus, effect of superdisintegrant ratio seems to be more

Table V. Validation of Response Surface Model

\begin{tabular}{|c|c|c|c|c|c|}
\hline Test & Test condition $\left(\mathrm{X}_{1}, \mathrm{X}_{2}\right.$ and $\left.\mathrm{X}_{3}\right)$ & Response & Experimental & Predicted & $\mathrm{PE}(\%)^{\#}$ \\
\hline \multirow[t]{4}{*}{ A } & $25 \% w / w$ & $\mathrm{Y}_{1}$ & 0.51 & 0.50 & 1.96 \\
\hline & $12.23 \% w / w$ & $\mathrm{Y}_{2}$ & 47.00 & 46.27 & 1.55 \\
\hline & 0.46 & $\mathrm{Y}_{3}$ & 88.22 & 84.96 & 3.70 \\
\hline & & $\mathrm{Y}_{4}$ & 160.00 & 163.00 & -1.88 \\
\hline \multirow[t]{4}{*}{ B } & $26.28 \% w / w$ & $\mathrm{Y}_{1}$ & 0.50 & 0.49 & 2.00 \\
\hline & $14.40 \% w / w$ & $\mathrm{Y}_{2}$ & 49.20 & 47.08 & 4.31 \\
\hline & 0.43 & $\mathrm{Y}_{3}$ & 87.90 & 87.13 & 0.88 \\
\hline & & $\mathrm{Y}_{4}$ & 190.00 & 198.00 & -4.21 \\
\hline \multirow[t]{4}{*}{$\mathrm{C}$} & $20 \% w / w$ & $\mathrm{Y}_{1}$ & 0.53 & 0.50 & 5.66 \\
\hline & $12.85 \% w / w$ & $\mathrm{Y}_{2}$ & 48.20 & 47.21 & 2.05 \\
\hline & 0.45 & $\mathrm{Y}_{3}$ & 88.04 & 85.19 & 3.24 \\
\hline & & $\mathrm{Y}_{4}$ & 175.00 & 174.00 & 0.57 \\
\hline
\end{tabular}


pronounced, as clearly depicted from Fig. 3b and Eq. 6. Analysis of variance (ANOVA) was applied for estimating the significance of the model at $5 \%$ significance level. From ANOVA, ratio of Indion 414: pharmaburst $500\left(\mathrm{X}_{3}\right)$ was found to exert significant effect on yield $(p<0.0001)$.

\section{Roundness}

The regression equation for roundness in actual values is given in Eq. 7. The equation represents the quantitative effect of factors $\left(X_{1}, X_{2}\right.$ and $\left.X_{3}\right)$ upon the response $Y_{3}$.

$\mathrm{Y}_{3}=106.81048+0.30711 \mathrm{X}_{1}-0.47738 \mathrm{X}_{2}-48.55948 \mathrm{X}_{3}(7)$

The influence of concentration of MCC, mannitol and ratio of superdisintegrants on roundness is shown in Fig. 4a, b. Graphical analysis shows that roundness varies in a linearly descending pattern with the change in factors. Results indicate that increasing the ratio of Indion 414:Pharmaburst 500 decreased roundness of pellets with higher value of coefficient than other two factors. Increasing the concentration of mannitol decreases the pellet roundness, while increasing the concentration of $\mathrm{MCC}$ increases the roundness. Thus, the effect of superdisintegrant ratio seems to be more pronounced, as clearly depicted from Fig. 4 and Eq. 7. Analysis of variance (ANOVA) was applied for estimating the significance of the model, at $5 \%$ significance level. From ANOVA, ratio of Indion 414: pharmaburst $500\left(\mathrm{X}_{3}\right)$ was found to exert significant effect on roundness $(\mathrm{p}<0.05)$.

\section{In Vitro Disintegration Time}

The regression equation for disintegration time in actual values is given in Eq. 8. The equation represents the quantitative effect of factors $\left(\mathrm{X}_{1}, \mathrm{X}_{2}\right.$ and $\left.\mathrm{X}_{3}\right)$ upon the response $\mathrm{Y}_{4}$.

$\mathrm{Y}_{4}=+403.82353+0.83333 \mathrm{X}_{1}+5.11111 \mathrm{X}_{2}-700.98039 \mathrm{X}_{3}$

The influence of concentration of MCC, mannitol and ratio of superdisintegrants on disintegration time is shown in Fig. 5. Graphical analysis shows that disintegration time varies linearly with the change in factors. Results indicated that increasing the ratio of Indion 414:Pharmaburst 500 decreased disintegration time of pellets with higher value of coefficient than other two factors $(p<0.0001)$. On the contrary, increase of mannitol and MCC concentration increased disintegration

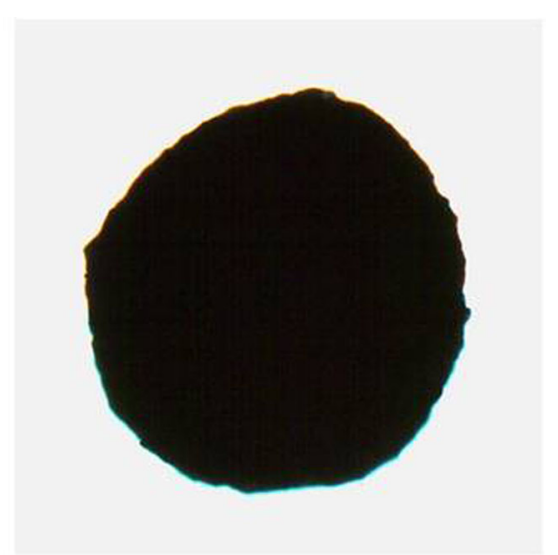

Fig. 6. Light microscopic image of optimized melt-in-mouth pellet formulation of Atomoxetine hydrochloride

time. Thus, the effect of superdisintegrant ratio seems to be more pronounced, as clearly depicted from ANOVA (Fig. 5 and Eq. 8).

\section{Optimization of the Pellet Formulation}

With the help of polynomial equations, the process was optimized for all the responses. The final optimal experimental parameters were calculated by satisfying the requirements for each response in the set. Thus, to obtain atomoxetine melt-in mouth pellets, it is desirable to minimize $\mathrm{Y} 1$, maximize $\mathrm{Y} 2$ and $\mathrm{Y} 3$ and minimize $\mathrm{Y} 4$. In this study, optimization was performed with constraints for Y1 $(<1 \%)$, Y2 (maximum), Y3 $(\approx 85)$ and Y4 (<1 min).

The optimized melt-in-mouth pellet formulation of atomoxetine hydrochloride thus obtained consist of $20 \%$ $w / w \mathrm{MCC}, 12.23 \% w / w$ mannitol and ratio of Indion 414: Pharmaburst being 0.46. The optimized melt-inmouth formulation was completely characterized for its yield, friability, shape, in vitro disintegration time, porosity, moisture uptake behaviour, surface characterization, drug release behaviour, sensory evaluation and in vivo disintegration time.

\section{Validation of Response Surface Model}

In order to assess the reliability of the developed mathematical model, it needs to be validated. A test corresponding to the composition of optimum pellet formulation and three additional random tests, apart from the 29 trial runs of experimental design, with conditions

Table VI. Porosity Analysis of the Melt-in-Mouth Pellets of Atomoxetine Hydrochloride

\begin{tabular}{lccc}
\hline & \multicolumn{2}{c}{ Pore size distribution } \\
\cline { 2 - 4 } Pore diameter ranges $(\mu \mathrm{m})$ & \multicolumn{2}{c}{ Relative volume $(\mathrm{cc} / \mathrm{g})$} \\
\cline { 2 - 4 } & Blank pellets & Unmasked pellets & Taste-masked pellets \\
\hline $20-2$ & 50.16 & 54.12 & 57.75 \\
AVERAGE PORE DIAMETER $(\mu \mathrm{M})$ & 2.055201 & 2.0834308 & 3.158556 \\
\hline
\end{tabular}



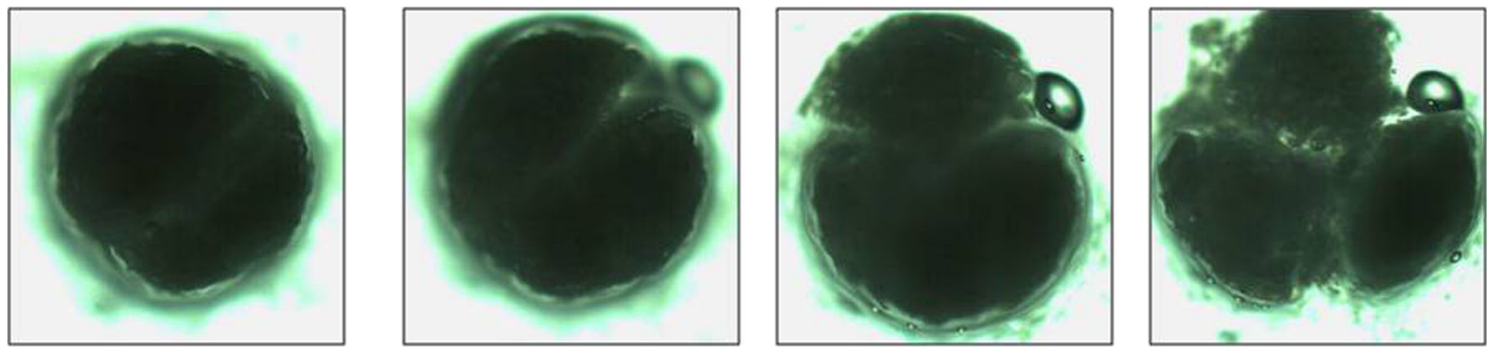

Fig. 7. Light microscopic images of melt-in-mouth atomoxetine hydrochloride pellet showing moisture uptake behaviour of pellet when wetted with water with in duration of $1 \mathrm{~min}$

covering the entire range of experimental domain was performed (Table V). For each of these test runs, responses were estimated by use of the generated mathematical model and by experimental procedures. Table VI lists the test conditions of the optimum and the random check points, their experimental and predicted values for response variables. Low value $(<5.0 \%)$ of prediction error ( $\% \mathrm{PE})$ indicates that the predicted and observed values are in good agreement (Table VI).

\section{Characterization and Evaluation of Optimized Melt-in-Mouth Pellet of Atomoxetine Hydrochloride}

\section{Usable Yield (\% Theoretical) of Optimized Melt-in-Mouth Pellet}

The usable yield of pellets was determined from sieve analysis which was found to be $80 \% \mathrm{w} / \mathrm{w}$. The pellet yield was calculated based on the pellet fraction between \#14/22 and presented as the percent of total pellet weight. The results show that usable yield is fairly high, even at low amount of MCC (i.e. 20\% w/w) (27). The inclusion of combination of superdisintegrants (Indion 414 and Pharmaburst) does not affect the usable yield of pellets.

\section{Pellet Sphericity and Shape Analysis of Optimized Melt-in-Mouth Pellet}

From our trials, it was difficult to judge and quantify the pellets in terms of its roundness only by visual observation. Figure 6 depicts light microscopic image of optimized pellet. Inspection of photograph suggested that the pellets were rather 'rounded' (i.e. still being considerably elongated with rounded edges, rather than complete spherical). Image analysis through software also confirmed that observed roundness or sphericity of optimized pellet was 83.43 and peripheral surface of pellet was slight irregular. Whereas sphericity of the perfectly spherical pellets
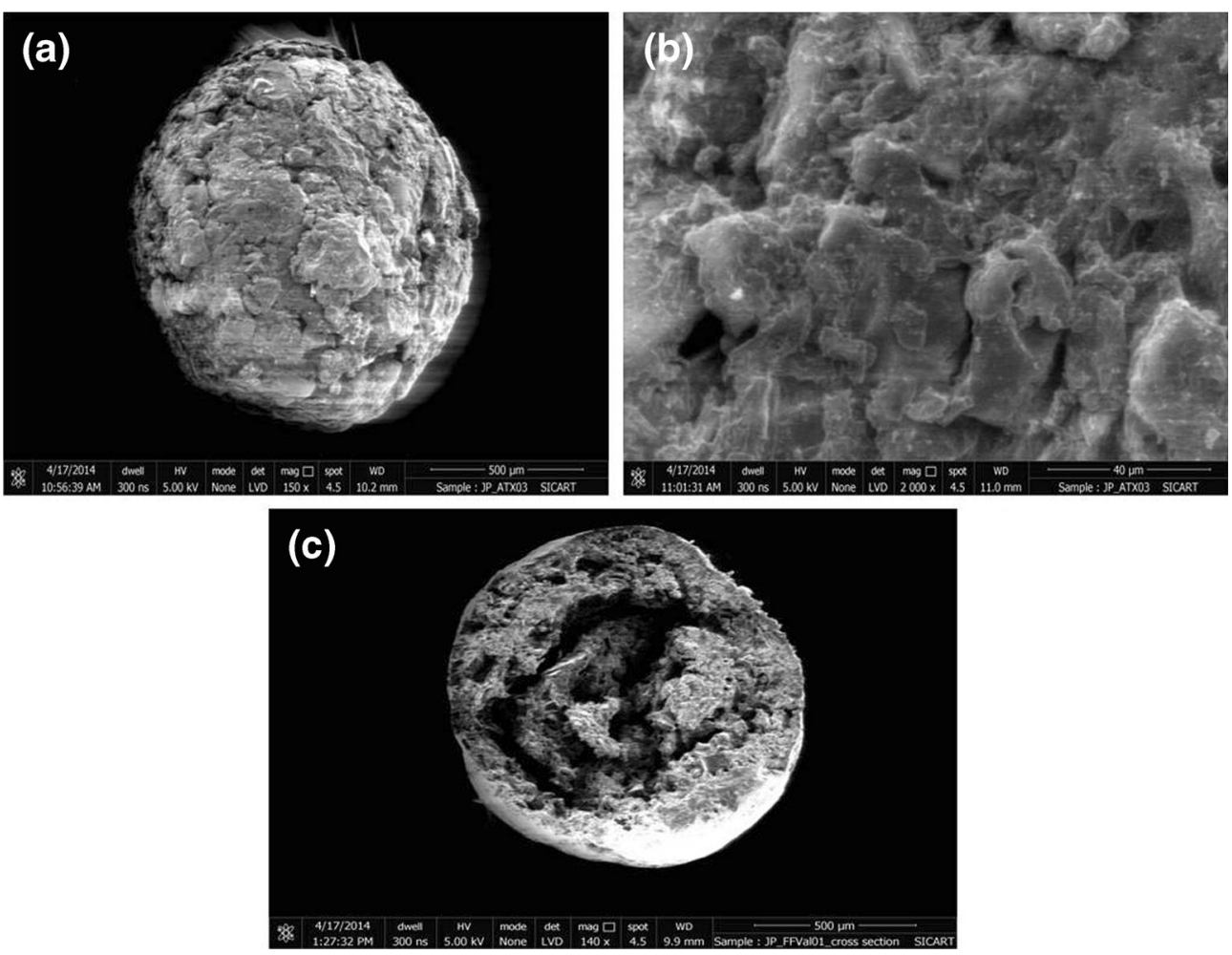

Fig. 8. SEM image of surface of melt-in-mouth pellet of atomoxetine hydrochloride $\mathbf{a}$ at $\times 150$ magnification, b at $\times 2000$ magnification and $\mathbf{c}$ SEM image of cross-section of melt-in-mouth pellet at $\times 150$ 
carries distinct advantages, such as ease of capsule filling due to better flow properties (26).

\section{Friability of Optimized Melt-in-Mouth Pellet}

Friability of the optimized pellet formulation was found to be $0.48 \%$ indicating that optimized pellets have sufficient abrasion resistance.

\section{In Vitro Disintegration Test of Optimized Melt-in-Mouth Pellet}

The optimized melt-in-mouth pellet formulation was found to be disintegrated within $30 \mathrm{~s}$ which fulfil the prespecified criteria of melt-in-mouth formulation (28).

\section{Porosity of Optimized Melt-in-Mouth Pellet}

The porosity of the optimized melt-in-mouth pellets was evaluated and enlisted in Table VI. It has been observed that taste-masked pellets have the highest average pore diameter, $3.16 \mu \mathrm{m}$, and also highest relative volume of the pores, $57.75 \mathrm{cc} / \mathrm{g}$, compared to blank and unmasked pellets. High pore volume and average pore diameter promote rapid water uptake and water channel formation in pellets, resulting into fast disintegration of melt-in-mouth atomoxetine hydrochloride pellets (26).

\section{Moisture Uptake Behaviour of Optimized Melt-in-Mouth Pellet}

Moisture uptake behaviour, as visualised at various time intervals (15 s) under light microscope, is shown in Fig. 7a-d. Melt-in-mouth pellet has a highly porous structure (Fig. 7a), and hence, it becomes imperative to study moisture uptake behaviour. The formation of aqueous channel in the pellets was observed as the pellet came in contact of water $(<1 \mathrm{~min})$. In Fig. $7 \mathrm{~b}$, aqueous channels formation initiated within few seconds eventually leading to the disintegration of the pellet matrix in $<1 \mathrm{~min}$ (Fig. 7c, d). The visual observations under the microscope have suggested that rapid disintegration of melt-in-mouth pellet occurred within few seconds and was initiated rapidly upon exposure to aqueous environment probably due to aqueous channel formation.

\section{Surface Characterization (SEM) of Optimized Melt-in-Mouth Pellet}

Further, to investigate the porous nature of melt-inmouth pellets, surface and cross-sectional characterization were carried out using SEM. Figure 8a, b clearly shows that the melt-in-mouth pellets do not exhibit smooth surface. Pores are clearly visible on the surface of pellets, which are possibly responsible for quick water uptake followed by subsequent disintegration of pellets by creating channelling effect. Cross-sectional view of melt-inmouth pellet also confirmed highly porous internal structure (Fig. 8c). This porous structure of melt-in-mouth pellets provided an added advantage in rapid disintegration along with the presence of superdisintegrants within pellet matrix (Fig. 8).

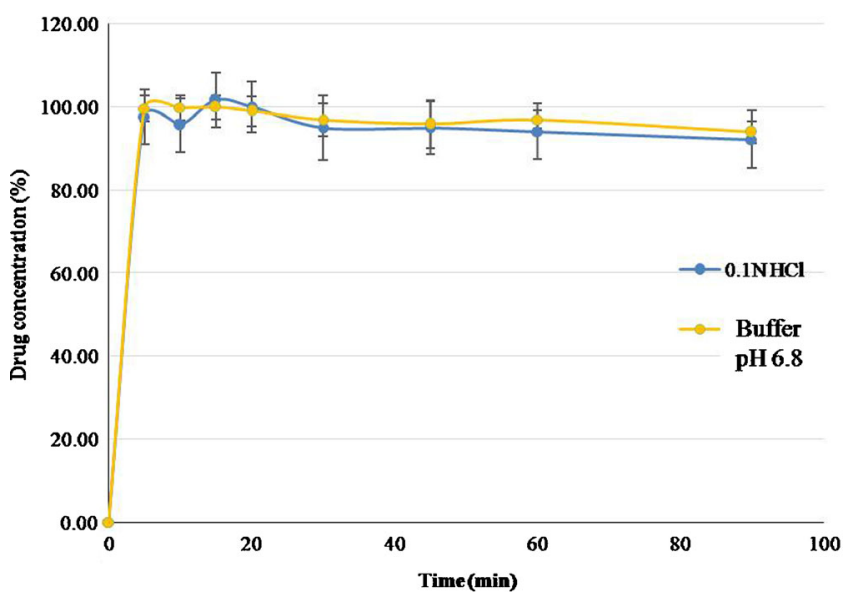

Fig. 9. Drug release from melt-in-mouth pellets of atomoxetine hydrochloride in USP apparatus III $(n=6)$

\section{Drug Release Study of Melt-in-Mouth Atomoxetine Hydrochloride Pellets}

Melt-in-mouth pellets released more than $95 \%$ of drug within $5 \mathrm{~min}$ in both dissolution media, viz. $0.1 \mathrm{~N} \mathrm{HCl}$ and PBS (pH 6.8), exhibiting an immediate drug release pattern (28). Fast disintegration of pellets and high solubility of drug can be attributed in the prompt dissolution (Fig. 9).

Sensory Evaluation for Taste Masking and In Vivo Disintegration Time of the Optimized Melt-in-Mouth Pellets of Atomoxetine Hydrochloride

The volunteers were asked to evaluate the taste-masked formulation as well as non-taste-masked formulations for their taste attribute and in vivo disintegration time, as per approved protocol. Forty percent of the volunteers ranked the tastemasked formulation as slightly bitter, while $60 \%$ of the volunteers ranked it no taste (Table VII). On the other hand, $70 \%$ of the volunteer's ranked non-taste-masked formulation as very

Table VII. Sensory Evaluation of Taste Masking and Disintegration Time of Pellets in Healthy Human Volunteers

\begin{tabular}{|c|c|c|}
\hline $\begin{array}{l}\text { Subject } \\
\text { ID }\end{array}$ & $\begin{array}{c}\text { Treatment A } \\
\text { (non-taste masked) } \text { (taste score) })^{\mathrm{a}}(\mathrm{DT} \\
{\text { time }, \mathrm{min})^{\mathrm{b}}}^{\mathrm{b}}\end{array}$ & $\begin{array}{l}\text { Treatment B } \\
\text { (taste masked) } \\
(\text { taste score })^{\mathrm{a}} \\
(\text { DT time }, \text { min })^{\mathrm{b}}\end{array}$ \\
\hline 01 & $(+),(>1)$ & $(+),(<1)$ \\
\hline 02 & $(++),(<1)$ & $(-),(<1)$ \\
\hline 03 & $(++),(<1)$ & $(+),(<1)$ \\
\hline 04 & $(++),(<1)$ & $(-),(<1)$ \\
\hline 05 & $(+),(<1)$ & $(-),(<1)$ \\
\hline 06 & $(++),(<1)$ & $(-),(>1)$ \\
\hline 07 & $(++),(<1)$ & $(-),(<1)$ \\
\hline 08 & $(++),(<1)$ & $(-),(<1)$ \\
\hline 09 & $(+),(<1)$ & $(+),(<1)$ \\
\hline 10 & $(++),(>1)$ & $(+),(<1)$ \\
\hline
\end{tabular}

${ }^{a}$ Score: (-) Not bitter, (+) slightly bitter, (++) very bitter, (+++) extremely bitter

${ }^{b}$ Disintegration time: less than $1 \min (<1)$, more than $1 \min (>1)$ 
bitter and $30 \%$ ranked it as slightly bitter. All the volunteers ranked taste-masked formulation to have better taste as compared to non-taste-masked formulation $(p<0.05)$. The volunteers were also asked to record their perception for disintegration time of same pellets into their mouth (Table VII). All the volunteers reported that pellets disintegrated within $1 \mathrm{~min}$, in the oral cavity, irrespective of taste-masked or non-taste-masked pellets.

The optimized melt-in-mouth pellets are basically meant for the rapid drug release and immediate availability of drug in the oral cavity for rapid absorption. Also, taste-masked melt-in-mouth formulation will avoid the reflex action (unlike other solid oral dosage forms which eventually might triggers vomiting) in paediatrics (29-31).

\section{CONCLUSION}

The atomoxetine hydrochloride melt-in-mouth pellets were prepared using extrusion-spheronization method and optimized using $3^{3}$ FFD. Most of pellets prepared with MCC using extrusion-spheronization method show a tendency to have a prolong drug release due to a lack of disintegration of pellets. However, the optimized spherical melt-in mouth Atomoxetine pellets, prepared using mannitol, Indion 414, Pharmaburst along with MCC, were conveniently administered in volunteers and disintegrated rapidly ( $<1 \mathrm{~min}$ ), both in vitro as well as in vivo. Melt-in-mouth pellets can be utilized as a simple and useful technology for drug administration to paediatric patients, conveniently and accurately with patient compliance. Melt-inmouth pellets will truly revolutionize the posology since dose can be easily adjusted by measuring a specific amount/number (each individual unit contains an estimated amount of drug) of the multi-particulates, depending on the patient's body weight. Apart from the dosing flexibility, melt-in-mouth pellets offers several advantages like; sprinkled on food, mixed with fluids or directly swallowed, improving patient compliance, disintegrate quickly in the oral cavity.

Importantly, the melt-in-mouth pellet dosage forms will also be well suited to be manufactured in several different sized dosage forms with minimal changes in set up of equipment, which will be an economically viable option for the pharmaceutical industries. A melt-in-mouth pellet seems to be a potential platform technology for pediatric population.

\section{ACKNOWLEDGMENTS}

The author gratefully acknowledges Sun Pharmaceuticals Ltd. (Vadodara), Corel Pharma Ltd. (Ahmedabad) and SPI Pharma (India) for providing the gift samples of drug and excipients. This work was funded by Department of Pharmaceuticals, Ministry of Chemicals and Fertilizers, Government of India to NIPER-Ahmedabad for carrying out the MS Pharm. work of JP. Authors are thankful to Dr. Manish Nivsarkar, Director, PERD Centre, Ahmedabad for allowing usage of clinical facilities and all volunteers including staff members who help to conduct the sensory evaluation study.

Conflict of Interest All authors declare no conflict of interest in the publication of manuscript.

\section{REFERENCES}

1. Krause J, Breitkreutz J. Improving drug delivery in paediatric medicine. Pharma Med. 2008;22:41-50.

2. Mohan MS. Pharmaceutical Development with focus on paediatric formulations. Mumbai: WHO / FIP Training Workshop; 2008.

3. Breitkreutz J, Boos J. Paediatric and geriatric drug delivery. Expert Opin Drug Deliv. 2007;4(1):37-45.

4. Nunn T, Williams J. Formulation of medicines for children. Br J Clin Pharmacol. 2004;59:674-6.

5. Siddiqui N, Garg G, Sharma P. Fast dissolving tablets: preparation, characterization and evaluation. Int J Pharm Sci Rev Res. 2010;4:87-96.

6. Standing JF, Tuleu C. Paediatric formulations-getting to the heart of the problem. Int J Pharm. 2005;300:56-66.

7. Shah RB, Collier JS, Sayeed VA, Bryant A, Habib MJ, Khan MA. Tablet splitting of a narrow therapeutic index drug: a case with levothyroxine sodium. AAPS PharmSciTech. 2010;11:1359-67.

8. Kayumba PC, Huyghebaert N, Cordella C, Ntawukuliryayo JD, Vervaet C, Remon JP. Quinine sulphate pellets for flexible pediatric drug dosing: formulation development and evaluation of taste-masking efficiency using the electronic tongue. Eur J Pharm Biopharm. 2007;66:460-5.

9. Sosnik A, Seremeta KP, Imperiale JC, Chiappetta DA. Novel formulation and drug delivery strategies for the treatment of pediatric poverty-related diseases. Expert Opin Drug Deliv. 2012;9:303-23.

10. Garland M, Kirkpatrick P. Atomoxetine hydrochloride. Nat Rev Drug Disco. 2004;3:385-6.

11. NIMH. Attention-deficit/hyperactivity disorder. Bethesda, USA: US Department of Health and Human Services, National Institutes of Health; 2012.

12. Mermey MS, Roy AK. Atomoxetine Solution. World Patent WO2014204513, December 24, 2014.

13. Venkatesh GM, Harmon TM, Taylor J. Orally disintegrating tablets of atomoxetine. US patent 8747895 B2, June 10, 2014.

14. Jain SP, Mehta DC, Shah SP, Singh PP, Amin PD. Melt-in-mouth pellets of fexofenadine hydrochloride using crospovidone as an extrusion-spheronisation aid. AAPS PharmSciTech. 2010;11(2):917-23.

15. Joshi A, Pund S, Nivsarkar M, Vasu K, Shishoo C. Dissolution test for site-specific release isoniazid pellets in USP apparatus 3 (reciprocating cylinder): optimization using response surface methodology. Eur J Pharm Biopharm. 2008;69:769-75.

16. Howard MA, Neau SH, Marvin JS. PEO and MPEG in high drug load extruded and spheronized beads that are devoid of MCC. Int J Pharm. 2006;307:66-76.

17. Koo OMY, Heng PWS. The influence of microcrystalline cellulose grade on shape and shape distributions of pellets produced by extrusion-spheronization. Chem Pharm Bull. 2001;49(11):1383-7.

18. Chopra R, Newton JM, Alderborn G, Podczeck F. Preparation of pellets of different shape and their characterization. Pharm Dev Technol. 2001;6:495-503.

19. Steckel H, Mindermann-Nogly F. Production of chitosan pellets by extrusion/spheronization. Eur J Pharm Biopharm. 2004;57:105-14.

20. Abdalla A, Mader K. Preparation and characterization of a selfemulsifying pellet formulation. Eur J Pharm Biopharm. 2007;66:220-6.

21. Tho I, Sande SA, Kleinebudde P. Disintegration pellets form a water insoluble pectin derivative produced by extrusion/ spheronisation. Eur J Pharm Biopharm. 2003;56:371-80.

22. Tripathi R, Mishra B. Preparation and evaluation of composite microspheres of polyacrylamide-grafted polysaccharide. J Appl Polym Sci. 2013;130:2912-22.

23. Rouseff RL, Matthews RF. Nomilin, Taste threshold and relative bitterness. J Food Sci. 1984;49:777-9.

24. Rowe RC, Sheskey PJ, Quinn ME. Handbook of pharmaceutical excipients. 6th ed. IL, USA: Pharmaceutical Press; 2009.

25. Pund S, Joshi A, Vasu K, Nivsarkar M, Shishoo C. Gastroretentive delivery of rifampicin: in vitro mucoadhesion and in vivo gamma scintigraphy. Int J Pharm. 2011;411:106-12.

26. Otero-Espinar FJ, Luzardo-Alvarez A, Blanco-Méndez J. NonMCC materials as extrusion-spheronization aids in pellets production. J Drug Deliv Sci Technol. 2010;20:303-18. 
27. Heng PWS, Koo OMY. A study of the effects of the physical characteristics of microcrystalline cellulose on performance in extrusion spheronization. Pharm Res. 2001;18(4):480-7.

28. Chamsai B, Sriamornsak P. Novel disintegrating microcrystalline cellulose pellets with improved drug dissolution performance. Powder Technol. 2013;233:278-85.
29. Buck ML. Alternative forms of oral drug delivery for pediatric patients. Pediatr Pharmacol. 2013;19:1-6.

30. Sosnik A, Carcaboso AM. Nanomedicines in the future of pediatric therapy. Adv Drug Deliv Rev. 2014;73:140-61.

31. Shukla D, Tripathi R, Mishra B. Taste masking in oral drug delivery systems: a technological update. Pharmstudent. 2010;25:58-64. 